\title{
Molecular Evidence for the Early Specification of Presumptive Functional Domains in the Embryonic Primate Cerebral Cortex
}

\author{
Maria J. Donoghue and Pasko Rakic \\ Yale University School of Medicine, Section of Neurobiology, New Haven, Connecticut 06510
}

To identify molecules that may play a role in the initiation of cerebral cortical area formation, we examined the expression of the Eph receptors and their ligands, the ephrins, during primate corticogenesis. We selected the macaque monkey neocortex because of its clear areal subdivisions, large surface area, protracted development (gestation $=165 \mathrm{~d}$ ), and similarity to the human brain. In situ hybridizations, performed at early [embryonic day 65 (E65)], middle (E80), and late (E95) stages of cortical development, revealed that EphA system family members are expressed in distinct gradients and laminar and areal domains in the embryonic neocortex. Indeed, several regionally restricted molecular patterns are already apparent within the cortical plate at E65, before the formation of thalamocortical connections, suggesting that the initial expression of some EphA system members is regulated by programs intrinsic to cortical cells. For example, EphA3, EphA6, and EphA7 are all selectively expressed within the presumptive visual cortex. However, although EphA6 and EphA7 are present throughout

The mature cerebral cortex can be divided into morphologically distinct, functionally dedicated, and stereotypically connected cytoarchitectonic areas (Brodmann, 1909). How might these cellular fields emerge during development? One hypothesis, put forth by classical anatomists and physiologists, is that cortical cells are initially unspecified and that their parcellation is determined by thalamic input (Creutzfeldt, 1977). Indeed, subsequent data support the idea that the differentiation and precise delineation of cytoarchitectonic areas depends critically on the interaction of target regions with thalamic inputs (Rakic, 1988; Sur et al., 1988; O'Leary, 1989; Roe et al., 1990; Schlaggar and O'Leary, 1991; Agmon et al., 1995; Molnar et al., 1998). An extension of this hypothesis is that embryonic cortical cells are actually heterogeneous, creating a crude blueprint or protomap of future functional domains. This protomap would initially direct associations among neighboring cortical cells, and it later attracts appropriate inputs, with intrinsic and extrinsic forces collaborating in the final assignment of region-specific properties (Rakic, 1988). In support of this concept, domain-specific molecular markers as well as

\footnotetext{
Received Jan. 6, 1999; revised April 6, 1999; accepted April 7, 1999.

This work was supported by a Life Sciences Research Foundation postdoctoral fellowship (M.J.D.) and grants from National Institutes of Health (P.R.). We thank Regeneron Pharmaceuticals, Inc., especially Nick Gale, for generously providing human Eph and ephrin cDNAs; Terri Beattie and Susan Morgenstern for providing animal care; and Grace Gray, Tarik Haydar, Nenad Sestan, and Mark Velleca for their comments on this manuscript. M.J.D. is grateful to Nenad Sestan and Ladislav Mrzljak for assistance with embryonic primate neuroanatomy.

Correspondence should be addressed to Dr. Pasko Rakic, Yale University School of Medicine, Section of Neurobiology, 333 Cedar Street, SHM/C303, New Haven, CT 06510.
}

Copyright (C) 1999 Society for Neuroscience $\quad 0270-6474 / 99 / 195967-13 \$ 05.00 / 0$ this region, EphA3 is only expressed in the prospective extrastriate cortex, suggesting that cortical cells harbor functional biases that may influence the formation of appropriate synaptic connections. Although several patterns of early gene expression are stable (e.g., EphA3, EphA4, and EphA6), others change as development proceeds (e.g., EphA5, EphA7, ephrin-A2, ephrin-A3, and ephrin-A5), perhaps responding to extrinsic cues. Thus, at E95, after connections between the cortical plate and thalamus have formed, receptor subtypes EphA3, EphA5, EphA6, and EphA7 and the ligand ephrin-A5 are expressed in posterior regions, whereas EphA4 and ephrin-A2 and ephrin-A3 are either uniformly distributed or anteriorly biased. Taken together, our results demonstrate molecular distinctions among cells of the embryonic primate neocortex, revealing hitherto unrecognized compartmentalization early in corticogenesis.

Key words: corticogenesis; Eph; ephrin; area-specific gene expression; protomap; specification regional differences in rates of cell division suggest that distinct populations of cells exist within the cerebral cortex (Barbe and Levitt, 1991; Arimatsu et al., 1992; Dehay et al., 1993; CohenTannoudji et al., 1994; Bulfone et al., 1995; Eagleson et al., 1997; Polleux et al., 1997; Na et al., 1998; Nothias et al., 1998). Furthermore, tissue culture, cell lineage, and transplantation studies testify that cortical cells exhibit certain phenotypic, laminar, and regional biases (Luskin et al., 1988; McConnell, 1988; Parnavelas et al., 1991; Ferri and Levitt, 1993; Tan et al., 1998). However, no molecule whose expression corresponds to particular presumptive cortical areas during their formation has been identified to date.

To identify and characterize molecular differences among developing functional domains, we chose to study the embryonic monkey cortex for several reasons. First, cytoarchitectonic areas are diverse and distinct. Second, a large portion of its $165 \mathrm{~d}$ gestation is devoted to the development of distinct components of the nervous system. This extended neural development results in the generation of cortical cells in the absence of connections between the cortex and the thalamus, effectively separating cortical development into two phases; the first is governed by intrinsic programs and the second is responsive to environmental factors (Rakic, 1976, 1977a,b). Third, the primate cortex has a large surface area, providing high spatial resolution. Fourth, an extensive body of work has recorded the generation of cells, the formation of connections, and the properties of synapses in the primate cortex, providing a rich context in which to interpret molecular patterns (Rakic, 1974; Shatz and Rakic, 1981; Kostovic and Rakic, 1984, 1990; Bourgeois and Rakic, 1993; Kennedy and Dehay, 1993; Dehay et al., 1996; Horton and Hocking, 1996). 
We set our sights on a group of molecules important in patterning in other developmental paradigms but whose roles in corticogenesis were unclear. The Eph system consists of Eph receptors (Class A or B) and either gpi-linked (ephrin-A) or transmembrane (ephrin-B) ligands (Tuzi and Gullick, 1994; Pandey et al., 1995; Eph Nomenclature Committee, 1997). Although promiscuous, EphA receptors tend to bind and be activated by ephrin-A ligands and EphBs by ephrin-Bs (Gale et al., 1996). Although members of these families have roles in many tissues (Patel et al., 1996; Wang and Anderson, 1997; Wang et al., 1998), some of their most striking effects are within the nervous system (Krull et al., 1997; Smith et al., 1997; Wang and Anderson, 1997). For example, in the retinotectal system, expression of ephrin-A2 and ephrin-A5 is graded within the tectum, retinal axons respond differentially to their presence, and animals lacking ephrin-A5 have distorted retinotectal maps (Cheng et al., 1995; Drescher et al., 1995; Feldheim et al., 1998; Frisen et al., 1998). Moreover, in the neuromuscular system, ephrin-A5 expression is positionally biased in skeletal muscle and affects axon outgrowth from peripheral nerves in a positional manner (Donoghue et al., 1996; Fukushima et al., 1996). Regarding cerebral cortical specificity, the contributions of the Eph system are not well known; however, two studies support their involvement. First, ephrin-A5 was isolated on the basis of its ability to bind to cortical axons and inhibit their fasciculation (Winslow et al., 1995). Second, in postnatal rodents, ephrin-A5 and EphA5 are segregated to specific portions of the cortex and the thalamus, respectively, and thalamic axons respond preferentially to ephrin-A5 (Zhang et al., 1996; Castellani et al., 1998; Gao et al., 1998). Now, to determine whether members of the Eph system are expressed during the establishment of cortical areas and, if they are, what their spatial and temporal distributions are, we examined this set of molecules in the developing macaque monkey cortex.

\section{MATERIALS AND METHODS}

Surgical procedures. Timed pregnant rhesus monkeys were obtained from the Yale primate breeding colony (New Haven, CT) and the New England Regional Primate Center (Southborough, MA) 65, 80, or 95 d after the estimated day of conception, and cesarean sections were performed as described previously (Rakic, 1972). Briefly, pregnant females were sedated with 5-10 mg/ $\mathrm{kg}$ ketamine and $0.2 \mathrm{mg} / \mathrm{kg}$ atropine sulfate, an intravenous catheter was introduced for fluid administration, and the abdomen was prepared under sterile conditions. Heart rate and respiration were monitored throughout the procedure, which was performed under isofluorane-oxygen inhalation anesthetic. A midline incision was made, the uterus was incised, the chorioallantoic membrane was punctured, and the embryo was delivered. Finally, the mother's uterus and abdominal walls were sutured, and her health was closely monitored for several days. Three animals at each embryonic age were examined.

Tissue preparation. Embryonic monkey brains were dissected and split into hemispheres. Each hemisphere was then placed on a thin layer of embedding media on a microscope slide and frozen by placing the slide on dry ice and sprinkling dry ice powder over the sample. After it was fully frozen, each sample was transferred to $-80^{\circ} \mathrm{C}$ and stored. On the first day of each in situ hybridization, the tissue was brought to $-20^{\circ} \mathrm{C}$, and cryostat sections of $10-20 \mu \mathrm{m}$ were cut and thaw-mounted onto silanated slides.

In situ hybridizations. In situ hybridizations were performed according to Donoghue et al. (1996). Briefly, slides containing freshly cut embryonic monkey brains were incubated in the following series of solutions at room temperature: (1) 4\% paraformaldehyde, $\mathrm{pH} 7$, for $10 \mathrm{~min}$, (2) PBS for $10 \mathrm{~min}$, (3) $0.75 \%$ glycine/PBS twice for 3 min each, (4) PBS for 5 min, (5) $0.1 \mathrm{M}$ triethanolamine (TEA) buffer for $5 \mathrm{~min}$, (6) $0.1 \mathrm{M}$ TEA containing $500 \mu \mathrm{l}$ acetic anhydride for $10 \mathrm{~min}$, (7) $0.1 \mathrm{M}$ TEA for $5 \mathrm{~min}$, (8) 50,70, 95, and $100 \%$ ethanol for $2 \mathrm{~min}$ each, (9) chloroform for $5 \mathrm{~min}$, (10) $100 \%$ ethanol twice for 2 min each. Probes were diluted in hybridization solution and denatured at $100^{\circ} \mathrm{C}$ for $2 \mathrm{~min}$. Hybridization solution containing probe $\left(3 \times 10^{6}\right.$ in a volume of $\left.120 \mu \mathrm{l}\right)$ was then spread over each section, and a coverslip was placed over this solution and sealed. Slides were then incubated in a humidified chamber at $65^{\circ} \mathrm{C}$ for at least $16 \mathrm{hr}$. After hybridization, slides were incubated in the following series of solutions: (1) $2 \times$ SSC for $15 \mathrm{~min}$ at room temperature, (2) $0.5 \times \mathrm{SSC}$ for $5 \mathrm{~min}$ at room temperature, (3) $0.1 \times \mathrm{SSC}$ for $20 \mathrm{~min}$ at $65^{\circ} \mathrm{C}$, (4) $1 \times$ RNase buffer for $5 \mathrm{~min}$ at $37^{\circ} \mathrm{C}$, (5) $20 \mu \mathrm{g} / \mathrm{ml}$ RNase A in $1 \times$ RNase buffer for $30 \mathrm{~min}$ at $37^{\circ} \mathrm{C}$, (6) $1 \times$ RNase buffer for $30 \mathrm{~min}$ at $37^{\circ} \mathrm{C},(7) 2 \times$ SSC for $30 \mathrm{~min}$ at room temperature, (8) $0.1 \times$ SSC twice for $10 \mathrm{~min}$ at $65^{\circ} \mathrm{C}$, (9) $0.1 \times \mathrm{SSC}$ for $30 \mathrm{~min}$ at room temperature, (10) 50, 70, 95, and $100 \%$ ethanol for $2 \mathrm{~min}$ each at room temperature. After exposure to film, slides were dipped in NTB2 nuclear track emulsion (Kodak, Rochester, NY), exposed for $\sim 1$ month at $4^{\circ} \mathrm{C}$, developed, lightly counterstained with hematoxylin and bis-benzamide, coverslipped in glycerol, and photographed with either dark-field, fluorescent, or bright-field optics.

Generation of primate antisense probes. Human or monkey template DNAs, corresponding to members of the EphA and ephrin-A families, were obtained either as the generous gift of Nick Gale (Regeneron Pharmaceuticals, Inc.) (Gale et al., 1996) or by RT-PCR and subsequent cloning and characterization from embryonic rhesus monkey brain RNA [according to Sambrook et al. (1989)]. These templates were then linearized, and antisense RNA probes were generated by in vitro transcription (Melton et al., 1984). The quality of the RNA probes was then confirmed by PAGE followed by autoradiography.

\section{RESULTS}

The developing cerebral wall in primates, as in other mammals, contains several transient embryonic zones (Sidman and Rakic, 1973; Rakic, 1977b; Kostovic and Rakic, 1990). These zones include (1) the ventricular zone (VZ), with its dividing neural progenitor cells; (2) the subventricular zone (SVZ), which acts early in corticogenesis as a secondary neuronal progenitor compartment and holding area for postmitotic cells from the VZ, and later in development as the major source of glia; (3) the intermediate zone (IZ), through which migrating neurons traverse along radial glial processes; (4) the subplate zone (SP), thought to be essential in orchestrating proper thalamocortical connectivity; (5) the cortical plate $(\mathrm{CP})$, the initial condensation of postmitotic neurons that will become the characteristic six-layered structure of the mature cortex, generated in a stereotyped inside-first, outside-last manner; and (6) the marginal zone (MZ), the most superficial, cell-sparse layer, important in the establishment of the laminar organization of the cortex. Notably, these zones are especially broad and pronounced in primates, enabling their visualization within the width of the cerebral wall at each developmental stage.

We have focused our study on three embryonic days (E): E65 (Figs. 1, 2), E80 (Figs. 3, 4), and E95 (Figs. 5, 6) of the macaque monkey's 165 d gestational period. These age groups were selected because they represent distinct phases of corticogenesis (Rakic, 1974, 1976, 1977b). For example, the neocortex at E65 is characterized by intensive proliferation of cells within the VZ and massive migration of postmitotic cells through the IZ. Moreover, cells have begun to condense after this migration, forming the CP. However, at this age zones within the cerebral wall still consist of mixed populations of cells, including an IZ that contains cells destined for the SP and a CP that consists of cells that will either comprise the SP or future layers V and VI of the mature cortex (Rakic, 1977b; Shatz and Rakic, 1981; Kostovic and Rakic, 1990). Furthermore, and important for our studies, axons from the thalamus have not yet invaded the cortical plate at E65 (Rakic, 1976, 1977b). In contrast, 2 weeks later at E80, the cerebral wall is significantly different: cells continue to proliferate and migrate, but now the CP is more substantial, including future layer IV cells, the prospective targets of thalamic inputs. Thalamic axons have not yet invaded the $\mathrm{CP}$; however, some are 

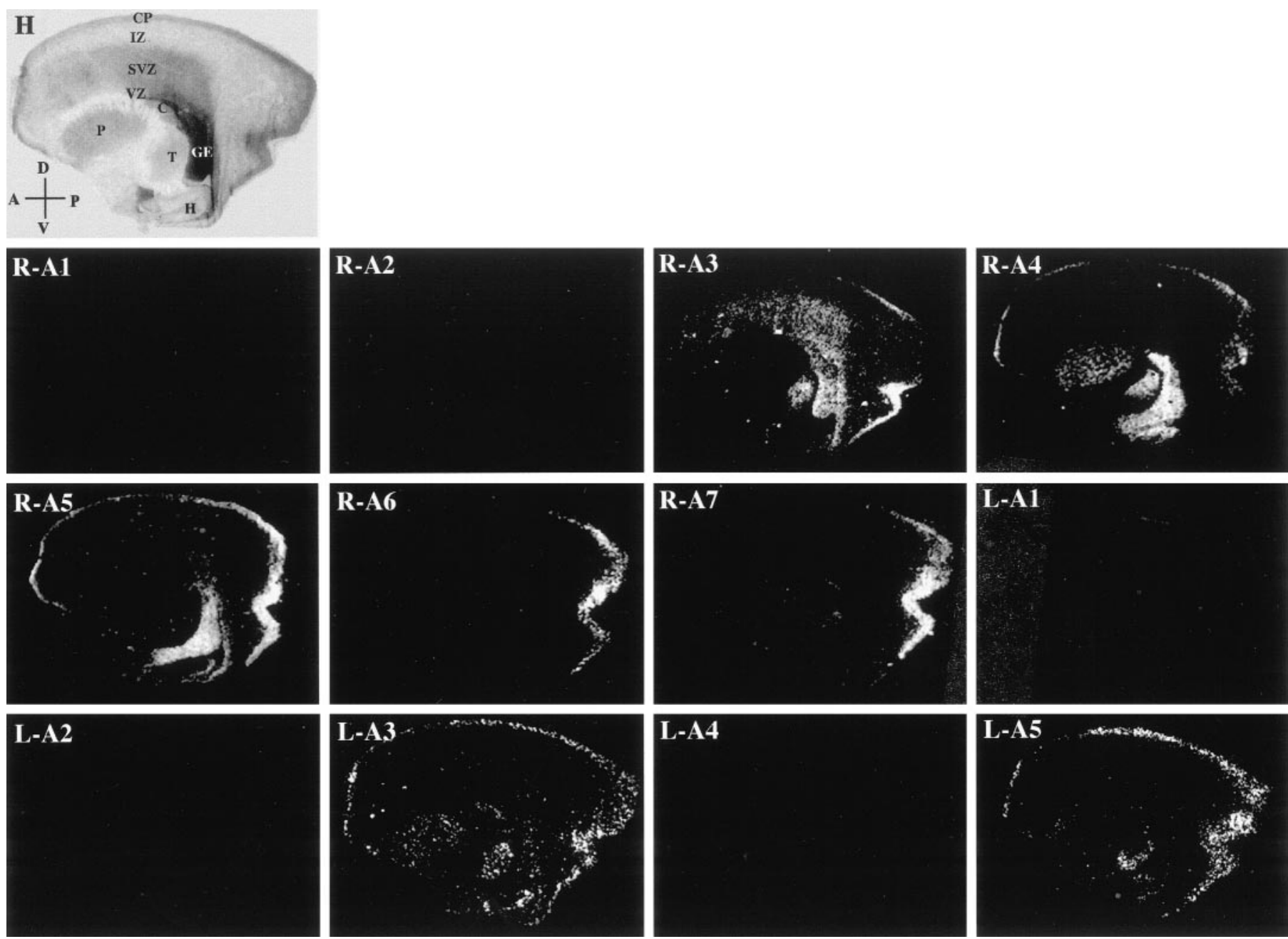

Figure 1. EphA and ephrin-A expression in the E65 macaque monkey brain. Low-power views $(1 \times)$ of parasagittal sections of an E65 rhesus monkey brain stained with hematoxylin $(H)$ or hybridized with radioactive antisense probes corresponding to EphA1 $(R-A 1)$, EphA2 $(R-A 2)$, EphA3 $(R-A 3)$, EphA4 (R-A4), EphA5 (R-A5), EphA6 (R-A6), EphA7 (R-A7), ephrin-A1 (L-A1), ephrin-A2 (L-A2), ephrin-A3 (L-A3), ephrin-A4 (L-A4), and ephrin-A5 $(L-A 5)$. Embryonic neocortical zones [ventricular zone $(V Z)$, subventricular zone $(S V Z)$, intermediate zone $(I Z)$, and cortical plate $(C P)]$ and non-neocortical structures [ganglionic eminence $(G E)$, putamen $(P)$, caudate $(C)$, thalamus $(T)$, and hippocampus $(H)$ ] are indicated in $A$ and refer to all panels. Anatomical coordinates are indicated in the bottom left corner of $H$ ( $A$, anterior; $P$, posterior; $D$, dorsal; $V$, ventral) and refer to Figures 3 and 5 as well.

present in the cerebral wall, waiting in the SP zone (Rakic, 1976). Similarly, pyramidal neurons of prospective layers V and VI have not yet extended their projections to their subcortical targets (Shatz and Rakic, 1981). In another 2 weeks, at E95, the neocortex enters a stage at which cell proliferation has virtually ceased, and the $\mathrm{CP}$ is well formed and has both extended axons toward and received inputs from the thalamus (Rakic, 1976, 1977b; Shatz and Rakic, 1981; Sidman and Rakic, 1982). Thus, these three embryonic ages represent the beginning, middle, and end of the formation of the cerebral cortex in the macaque monkey, and they correspond to periods that precede, are coincident with, and follow the initial formation of connections between the cortical plate and the thalamus.

Here we describe patterns of EphA and ephrin-A gene expression at each of these three embryonic ages, both along the cortex's anteroposterior axis and within its embryonic zones. These data are presented as in situ hybridizations of sagittal sections because this view reveals the greatest number of future functional areas, arrayed along the cortex's anteroposterior (rostrocaudal) axis, as well as the embryonic zones of the cerebral wall. The data presented at each age consist of a pair of figures. The first of each pair (Figs. 1, 3, 5) presents low-power views to illustrate general patterning and zone specificity within the neocortex, whereas the second figure in each pair (Figs. 2, 4, 6) consists of higher-power views of the region surrounding the $\mathrm{CP}$, to demonstrate laminarand zone-specific expression. All of the results presented in this paper are summarized in Table 1. Finally, although the EphA receptors and the ephrin-A ligands are widely expressed throughout the embryonic primate forebrain, we will limit our comments in this paper to their expression within the neocortex.

\section{Expression patterns at E65}

EphA1, EphA2, ephrin-A1, ephrin-A2, and ephrin-A4 are not expressed within the cerebral wall at E65 (Fig. 1, $R-A 1, R-A 2$, $L-A 1, L-A 2$, and $L-A 4$, respectively). However, other family members are and their expression is detailed below.

\section{EphA3}

EphA3 is absent from the VZ and MZ, but it is present at low levels within the IZ and is strongly expressed by cells of the SVZ. 

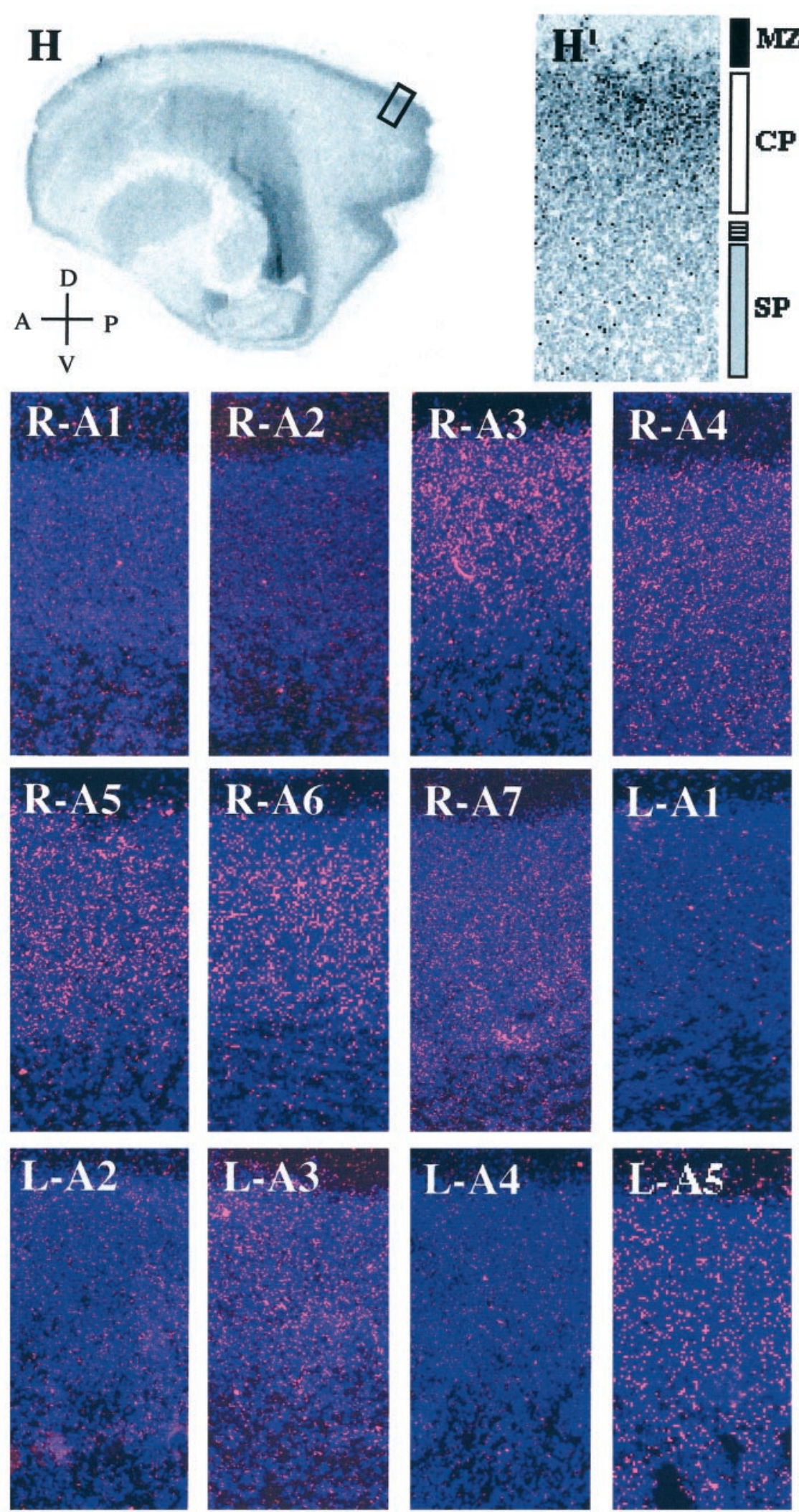

Moreover, within the SVZ, EphA3 is present in a posterior-highanterior-low pattern. In contrast, narrowly defined regions of the posterior cortical plate contain cells that express EphA3 (Fig. 1, $R-A 3)$. In particular, EphA3 is expressed by cells within the ventral-most and dorsal-most regions of the posterior $\mathrm{CP}$. Intrigu- ingly, this pattern of expression is reminiscent of the future location of the extrastriate cortex, whereas the region of the prospective striate cortex is devoid of EphA3 expression. Finally, within the CP, EphA3 is expressed by cells within its most superficial two-thirds (Fig. 2, $R$ - $A 3$ ). 

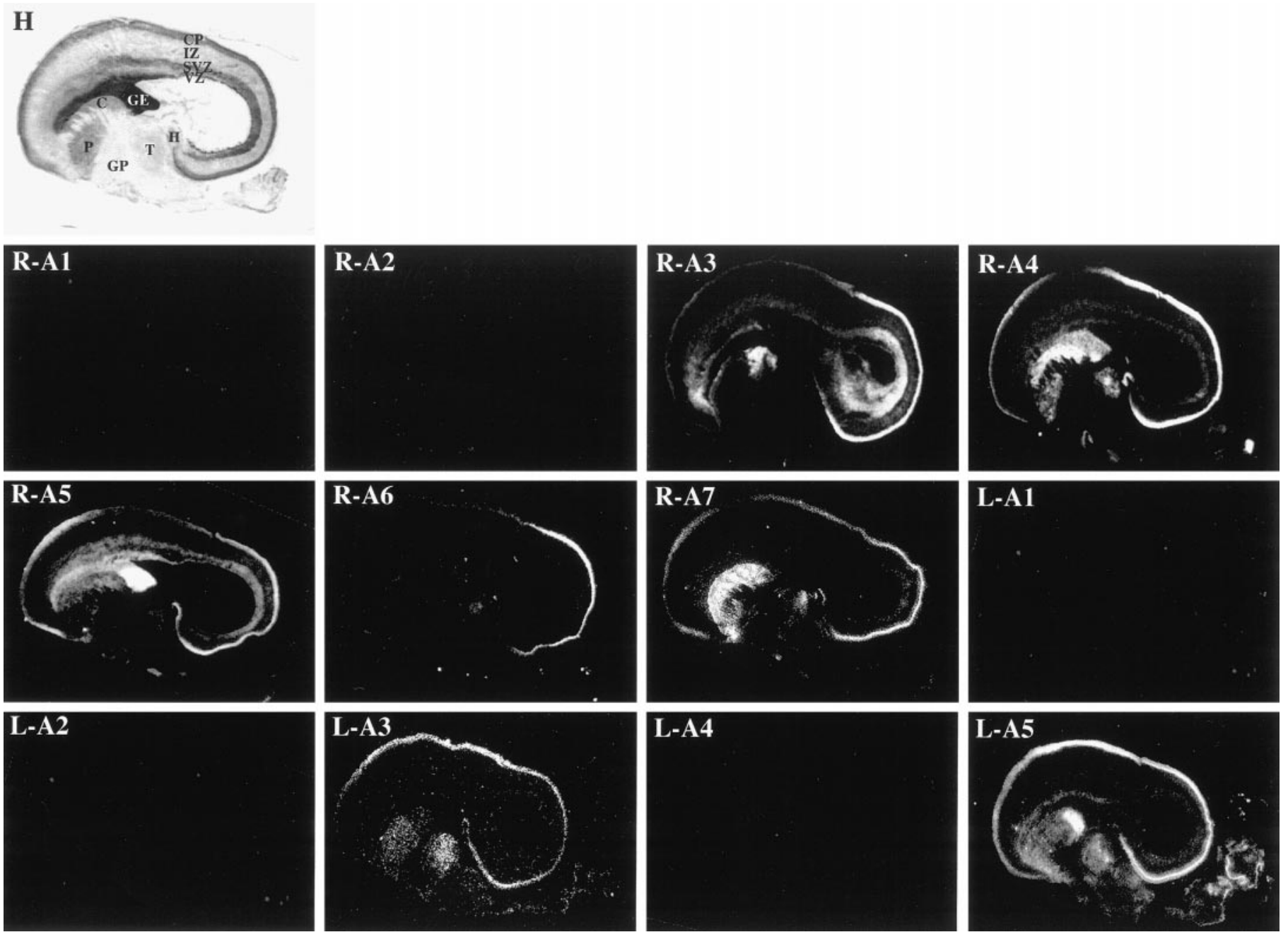

Figure 3. Expression of the EphA receptors and ephrin-A ligands in the E80 macaque monkey brain. Low-power $(1 \times)$ views of adjacent parasagittal sections of E80 rhesus monkey brains stained with hematoxylin $(H)$ or processed for radioactive $i$ situ hybridization. Sections hybridized with antisense probes corresponding to EphA1 $(R-A 1)$, EphA2 $(R-A 2)$, EphA3 $(R-A 3)$, EphA4 $(R-A 4)$, EphA5 $(R-A 5)$, EphA6 $(R-A 6)$, EphA7 $(R-A 7)$, ephrin-A1 $(L-A 1)$, ephrin-A2 ( $L-A 2)$, ephrin-A3 ( $L-A 3)$, ephrin-A4 $(L-A 4)$, and ephrin-A5 ( $L-A 5)$ are shown. Embryonic neocortical zones [ventricular zone $(V Z)$, subventricular zone $(S V Z)$, intermediate zone $(I Z)$, and cortical plate $(C P)$ ], as well as non-neocortical regions [ganglionic eminence $(G E)$, caudate $(C)$, putamen $(P)$, globus pallidus $(G P)$, thalamus $(T)$, and hippocampus $(H)]$, are labeled in $H$, and these labels correspond to all sections. Anatomical coordinates for this figure are as in Figure 1.

\section{EphA4}

Expression of EphA4 within the cerebral wall is restricted to the $\mathrm{SP}$ and $\mathrm{CP}$ and is absent from all other embryonic zones (Fig. 1, $R$ - $A 4$ ). Furthermore, uneven expression is observed along the full extent of the cortex's anteroposterior axis. Where it is expressed, however, EphA4 is present across the entire thickness of the $\mathrm{CP}$ (Fig. 2, R-A4).

\section{EphA5}

This molecule is expressed within the $\mathrm{CP}$, with the highest levels anteriorly and posteriorly and reduced levels in between (Fig. 1, $R-A 5$ ). Within the CP, EphA5 is uniformly expressed (Fig. 2, $R-A 5)$.

\section{EphA6}

EphA6 is present only within the posterior-most region of the CP (Fig. 1, R-A6). Moreover, in contrast to the expression of EphA3 at this age, EphA6 is expressed throughout the occipital lobe, in both presumptive striate and extrastriate regions. Finally, EphA6 is expressed by cells within the deepest two-thirds of the CP (Fig. 2, $R-A 6)$.

\section{EphA7}

EphA7, like EphA6, is present in a well defined posterior region of the CP; however, its pattern of expression is slightly expanded in comparison. Although its anteroposterior borders of expression are similar to those of EphA6 (Fig. 1, R-A7), EphA7 is expressed more extensively throughout the SP and CP. Within the $\mathrm{CP}$, its expression is consistent with it being present within cells that will constitute layers V and VI (Fig. 2, R-A7).

ephrin-A3

ephrin-A3 is present in a punctate pattern within the forming SP and $\mathrm{CP}$, along its full anteroposterior extent and within all of its prospective laminae (Figs. 1, $L-A 3,2, L-A 3$ ). 

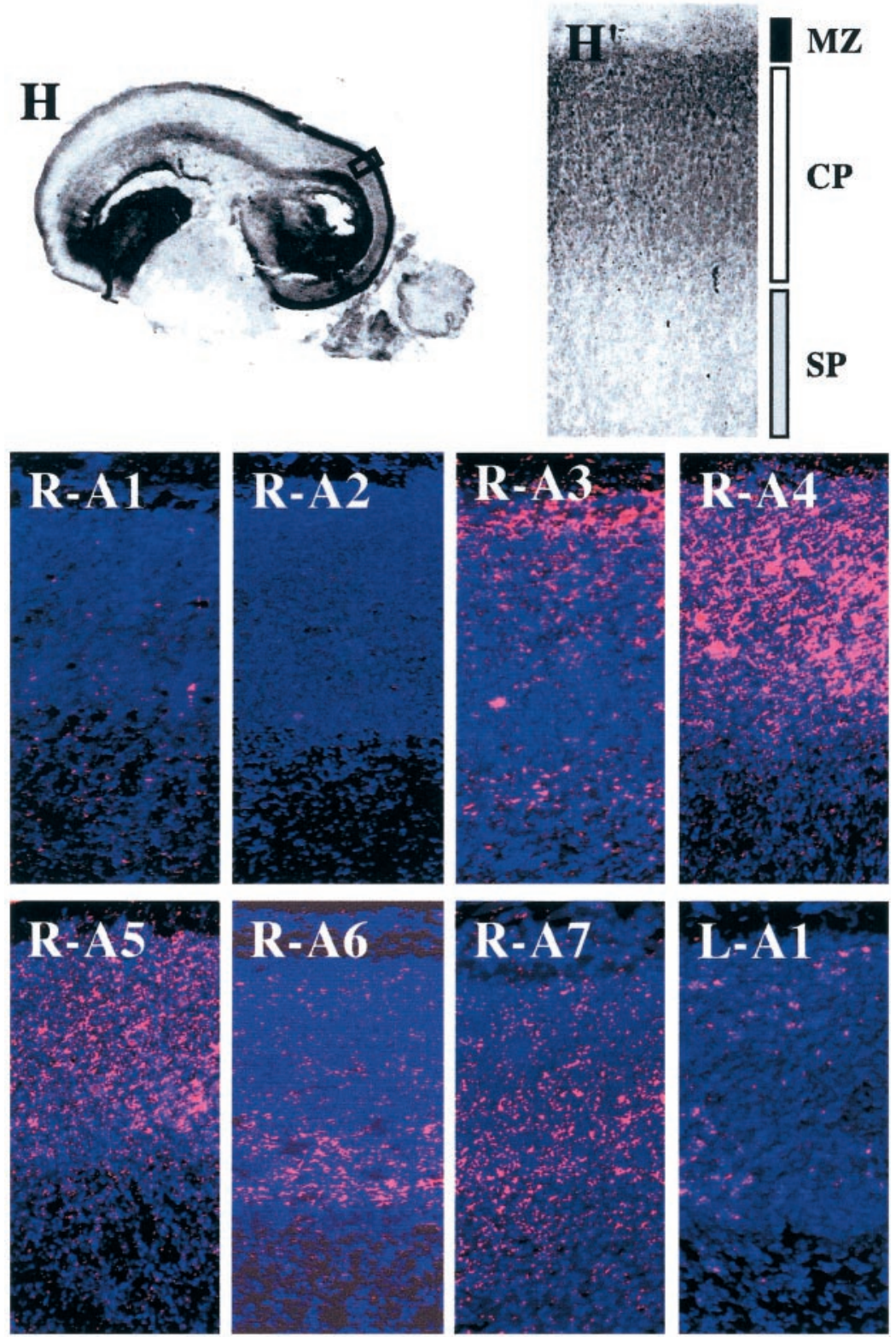

of EphA and ephrin-A family members in the E80 macaque neocortex. A low-power view $(1 \times)$ of a parasagittal section of an E80 monkey brain $(H)$ in which the region of the posterior cortical plate within the box corresponds to the higherpowered $(10 \times)$ images shown in the remaining panels. $H$ and $H^{\prime}$ are low- and high-powered views, respectively, of hematoxylin-stained tissue. Regions corresponding to the marginal zone ( $M Z$, black bar), cortical plate $(C P$, white bar), and subplate zone (SP, gray plate) are indicated in $H^{\prime}$ and refer to all of the following panels, which are images of radioactive in situ hybridizations using antisense probes corresponding to EphA1 $(R-A 1)$, EphA2 (R-A2), EphA3 (R-A3), EphA4 $(R-$ $A 4)$, EphA5 $(R-A 5)$, EphA6 $(R-A 6), \quad$ EphA7 $(R-A 7)$, ephrin-A1 (L-A1), ephrin-A2 (L-A2), ephrin-A3 ( $L-A 3)$, ephrin-A4 $(L-A 4)$, and ephrin-A5 $(L-A 5)$. Silver grains are pink, and bis-benzamide staining is in blue. Anatomical coordinates for this figure are as indicated in Figure 2.
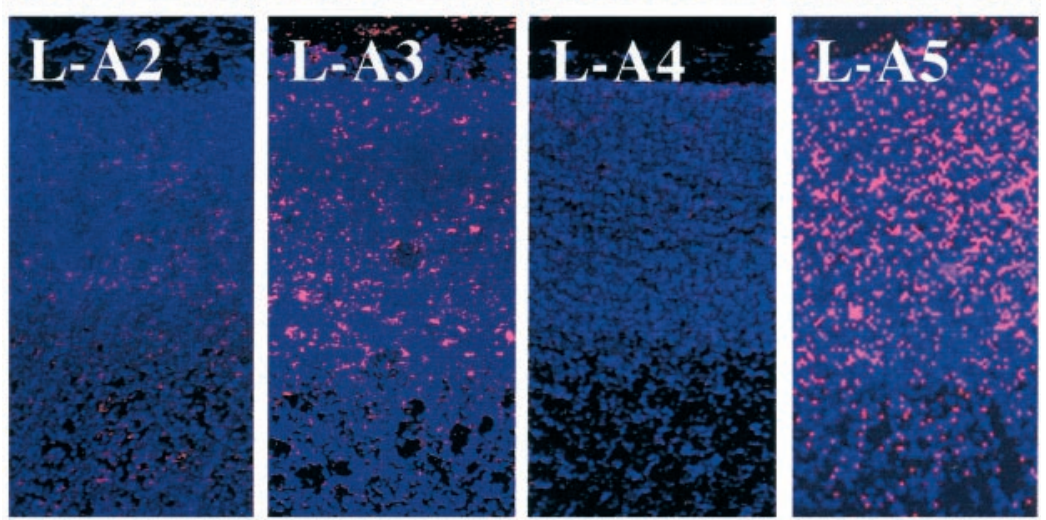

\section{ephrin-A5}

ephrin-A5 is expressed throughout the span of the CP (Fig. 1, $L-A 5)$. Within the CP, expression is uniform (Fig. 2, $L-A 5$ ).

Together, the expression patterns of the EphA receptors and ephrin-A ligands at E65 demonstrate marked regional and lami- nar differences. Such early patterns of gene expression are especially interesting because they are present in the absence of thalamic innervation of the $\mathrm{CP}$, suggesting that intrinsically encoded cellular heterogeneities within the neocortex exist during the early stages of its formation. 

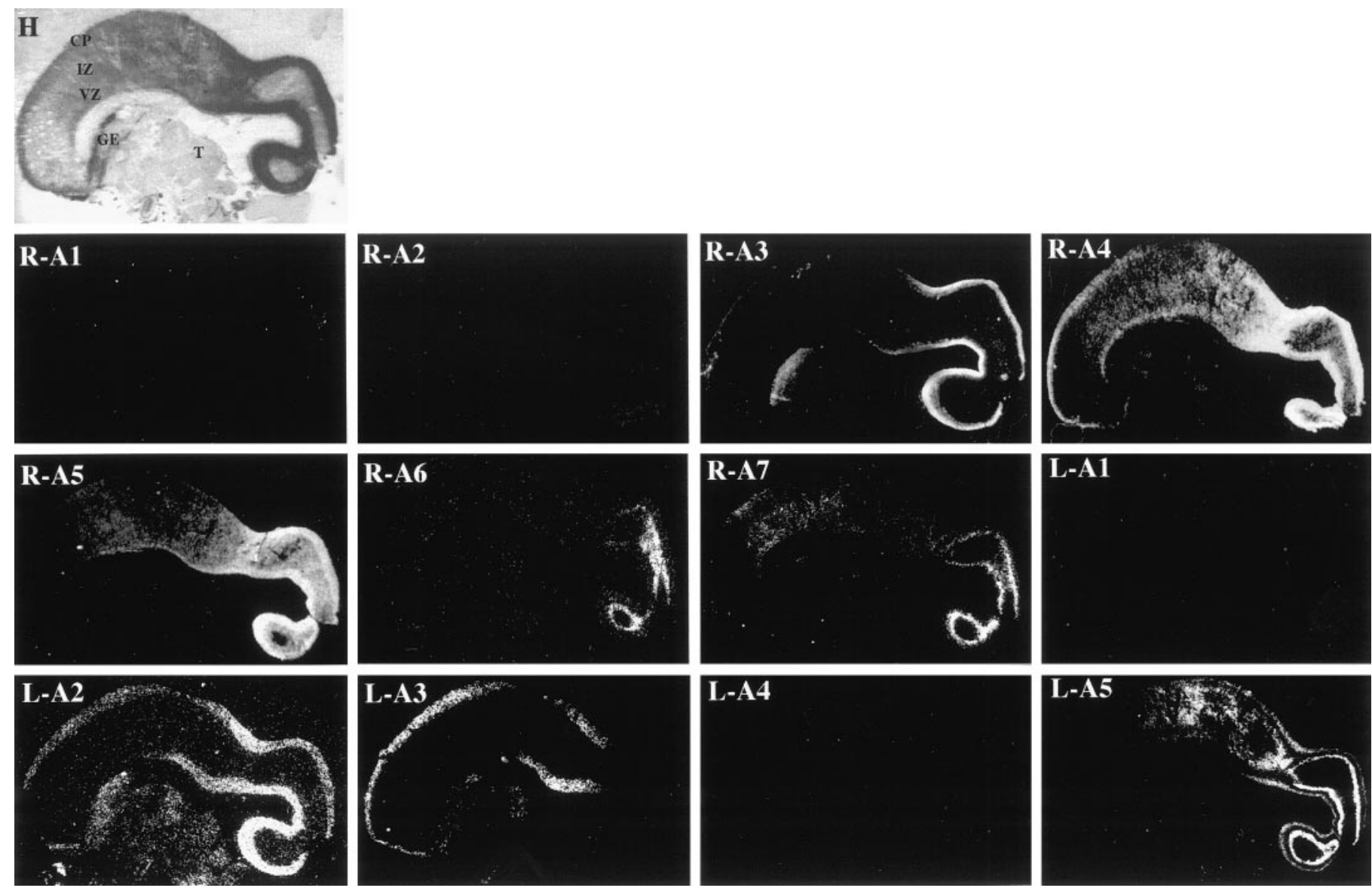

Figure 5. Region-specific expression of EphA and ephrin-A family members within the E95 macaque monkey brain. Low-power views $(0.75 \times)$ of medial parasagittal sections of an E95 rhesus monkey brain, stained with hematoxylin $(H)$ or hybridized with radioactive antisense probes to EphA1 $(R-A 1)$, EphA2 $(R-A 2), \operatorname{EphA3}(R-A 3), \operatorname{EphA} 4(R-A 4), \operatorname{EphA5}(R-A 5)$, EphA6 $(R-A 6)$, EphA7 $(R-A 7)$, ephrin-A1 $(L-A 1)$, ephrin-A2 $(L-A 2)$, ephrin-A3 $(L-A 3)$, ephrin-A4 ( $L-A 4)$, and ephrin-A5 ( $L-A 5)$. Embryonic zones [ventricular zone (VZ), intermediate zone (IZ), and cortical plate $(C P)$ ] and non-neocortical regions [ganglionic eminence $(G E)$, thalamus $(T)$ ] are indicated in $H$ and refer to all panels. Anatomical coordinates for this figure are as indicated in Figure 1.

\section{Expression patterns at E80}

Next, we examined members of the EphA system at E80. As at E65, there is robust cell proliferation and migration within the cortical wall at E80. In contrast, however, the $\mathrm{CP}$ region at this stage is much better defined, and thalamic axons are present within the cerebral wall, waiting within the SP zone before their invasion into the CP.

EphA1, EphA2, ephrin-A1, ephrin-A2, and ephrin-A4 are not expressed within the neocortex at E80 (Fig. 3, $R-A 1, R-A 2, L-A 1$, $L-A 2, L-A 4$, respectively). However, all other family members were present in distinct patterns, and the pattern of each expressed molecule is described briefly below.

\section{EphA3}

EphA3 is not expressed within either the VZ or MZ, but it is present at low but detectable levels in the IZ and SP. Furthermore, EphA3 is strongly expressed by cells of the SVZ and CP at E80 (Fig. 3, R-A3). Indeed, within each of these embryonic zones, EphA3 is differentially expressed; it is present at highest levels within the most posterior regions of the neocortex. Furthermore, EphA3 is expressed by the most superficial layer of the cortical plate at this stage, which are the cells that will give rise to future layer IV (Fig. 4, $R$ - $A 3$ ).

\section{$\operatorname{EphA4}$}

EphA4 is expressed within the CP and to a lesser extent the IZ and SVZ, but it is absent from the SP and VZ at E80 (Fig. 3, $R-A 4)$. Within the cortical plate, its expression is patterned: levels are high posteriorly, low in the middle, and intermediate anteriorly. In contrast to EphA3, EphA4 expression has a more anterior boundary of expression, encompassing the posterior two-thirds of the CP. Moreover, within the CP, EphA4 is present throughout, consistent with its expression by cells that will populate future layers IV, V, and VI (Fig. 4, $R$ - $A 4$ ).

\section{EphA5}

In contrast with the previous two EphA receptors, EphA5 is present within all zones of the embryonic cortex, including the VZ, SVZ, and CP, and to a lesser extent, the IZ, SP, and MZ (Fig. 3, R-A5). EphA5 is present throughout the CP's anteroposterior extent, although the middle section has lower levels than neighboring areas. Finally, EphA5 is in all strata of the CP (Fig. 4, $R-A 5)$.

\section{EphA6}

EphA6 is expressed exclusively within a single domain of the E80 cortical wall (Fig. 3, $R$ - $A 6$ ), the most posterior one-third, a region 

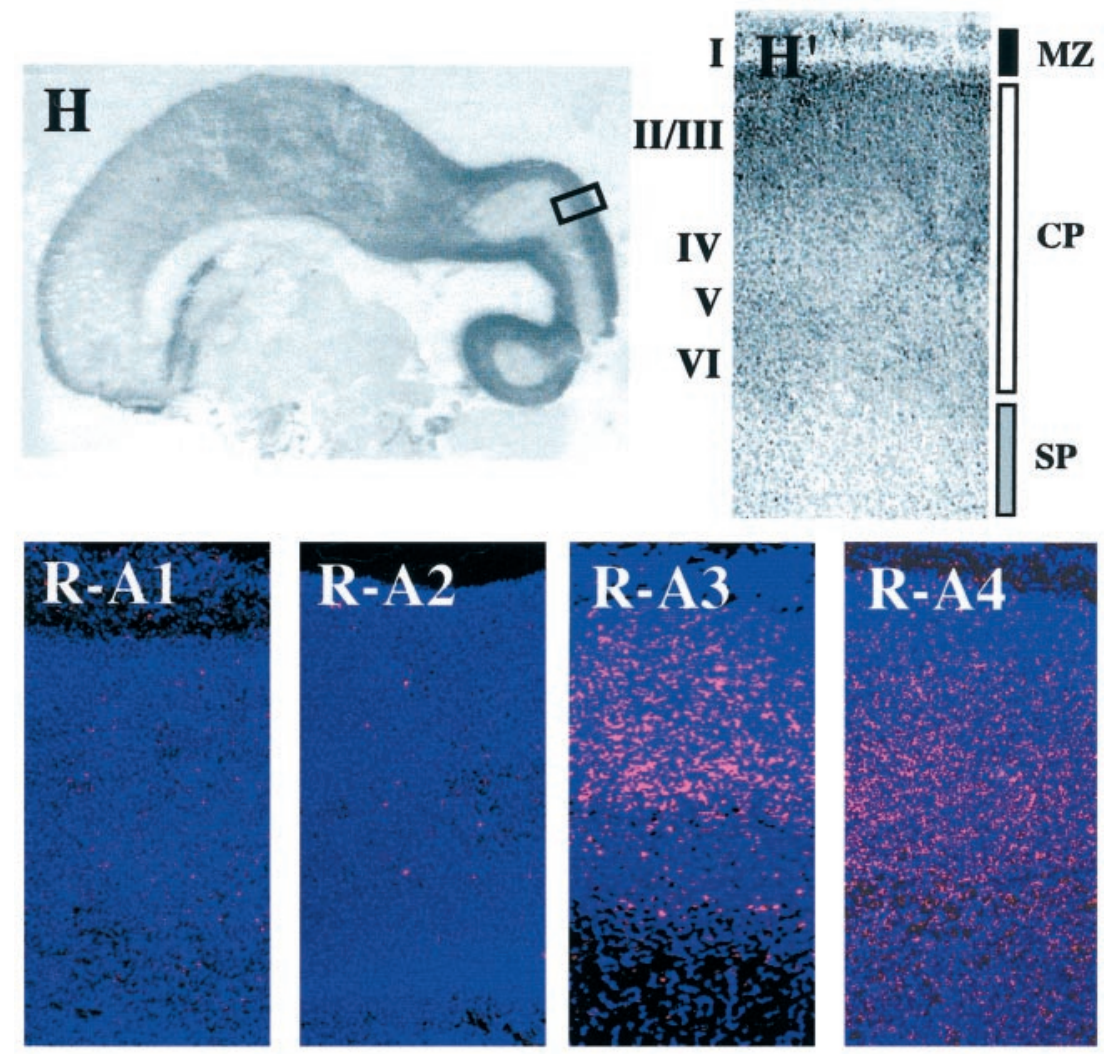

Figure 6. Laminar- and zone-specific patterns of EphA and ephrin-A gene expression in the E95 macaque neocortex. A low-power view $(1 \times)$ of a hematoxylin-stained section of an E95 monkey brain $(H)$ in which the area indicated by the box is shown at higher power $(4 \times)$ in $H^{\prime}$ and similar areas of additional sections in the remaining panels. Embryonic zones [marginal zone (MZ, black bar), cortical plate $(C P$, white bar), and subplate zone (SP, gray bar)] are indicated to the right, and tentative designations of future cortical layers $(I, I I / I I I, I V, V, V I)$ are shown on the left of $H^{\prime}$. These zones and layers refer to all panels, which correspond to radioactive in situ hybridizations using probes to EphA1 (R-A1), EphA2 (R-A2), EphA3 $(R-A 3)$, EphA4 $(R-A 4)$, EphA5 $(R-A 5)$, EphA6 $(R-A 6)$, EphA7 (R-A7), ephrin-A1 (L-A1), ephrin-A2 ( $L-A 2)$, ephrin-A3 ( $L-A 3)$, ephrin-A4 $(L-A 4)$, and ephrin-A5 ( $L$ $A 5)$ in which silver grains are shown in pink and bisbenzamide staining is in blue. Anatomical coordinates for this figure are indicated in the bottom left corner of $H$ in Figure 2.
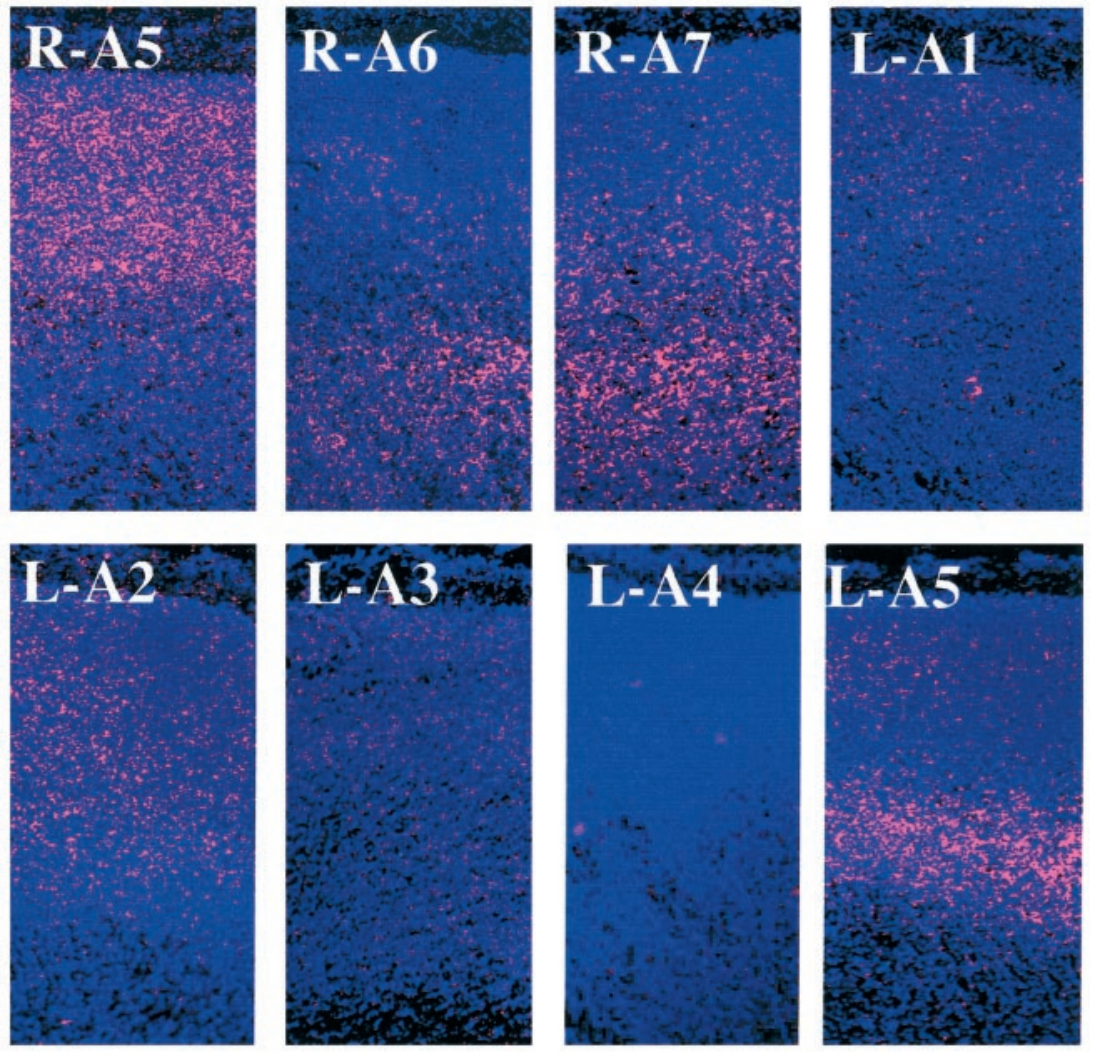

that is consistent with the location of the future visual cortex (Rakic, 1976; Kostovic and Rakic, 1984; Dehay et al., 1996). Moreover, a single band of cells in the deep CP and SP is EphA6 positive (Fig. 4, R-A6).

\section{EphA7}

EphA7 is also expressed by the developing neocortex, mainly in the SP and CP, with low levels of expression within the posteriormost SVZ (Fig. 3, $R$ - $A 7$ ). There is a gradient of expression within 


\begin{tabular}{llll}
\hline \multicolumn{1}{l}{ Table 1. Summary of the expression of EphA and ephrin-As in the } \\
macaque
\end{tabular}

Patterns of expression for the genes listed to the left are detailed at E65, E80, and E95. For each gene, the top line indicates the embryonic zones within which it is expressed, whereas the bottom line details its anteroposterior specificity, and separated by a semicolon, its laminar specificity within the cortical plate. -, No expression; VZ, ventricular zone; SVZ, subventricular zone; IZ, intermediate zone; SP, subplate; CP, cortical plate; MZ, marginal zone; even, uniformly expressed; upper, within superficial strata of the cortical plate; deep, within deeper strata of the cortical plate; A, anterior cortical plate; M, middle cortical plate; P, posterior cortical plate; I-VI, future cortical plate layers I through VI.

the CP that has an anterior boundary similar to that of EphA4. Within the CP, EphA7 expression is consistent with its presence in cells that will populate the deep layers, future layers $\mathrm{V}$ and $\mathrm{VI}$ (Fig. 4, R-A7). Thus, once again, EphA7's expression pattern overlaps considerably with that of EphA6; however, it is more extensive.

\section{ephrin-A3}

ephrin-A3 is expressed at low levels in the CP and is absent from all other embryonic zones of the developing cerebral wall (Fig. 3, $L-A 3)$. Within the cortical plate, its expression is highest in middle regions, with lower levels posteriorly and little expression anteriorly. Finally, ephrin-A3 is expressed throughout the CP [Fig. 4, $L-A 3$ (and data not shown)].

\section{ephrin- $A 5$}

At this age, expression of ephrin-A5 is robust throughout the $\mathrm{CP}$, with undetectable levels in other zones (Fig. 3, L-A5). Unlike other members of this family, ephrin-A5 expression is not biased along the cortex's anteroposterior axis. Moreover, ephrin-A5 is slightly laminar-specific, with the highest levels in intermediate regions of the $\mathrm{CP}$, consistent with this gene being expressed by cells of future layer $\mathrm{V}$ (Fig. 4, $L-A 5$ ).

Taken together, patterns of EphA and ephrin-A gene expression remain diverse within the E80 neocortex, both laminarly and areally. Although some patterns of expression were maintained from E65 to E80 (e.g., EphA4, EphA5, EphA6, ephrin-A3, and ephrin-A5), others were significantly expanded (e.g., EphA3 and EphA7).

\section{Expression patterns at E95}

To investigate whether the patterns of gene expression that we observed at earlier stages (E65 and E80) were maintained in late phases of corticogenesis, we examined the expression of the EphA receptors and ephrin-A ligands at E95. This was especially important for identifying whether differences in gene expression might be functionally related, because developmental gradients exist during the formation of the neocortex; early in development, posterior regions such as visual cortex are slightly more mature than frontal regions. However, by E95, these developmental gradients are largely gone. In addition to normalizing developmental differences, E95 in macaque monkey corresponds to the end of cortical neurogenesis: neurons of all layers are present within the $\mathrm{CP}$, and thalamocortical fibers are forming synapses within their cortical targets (Rakic, 1976, 1977b; Sidman and Rakic, 1982). Thus, examining gene expression at E95 allows us to determine the stability of patterns that we observed earlier in corticogenesis and to assess the potential effects of afferent innervation on these patterns.

EphA1, EphA2, ephrin-A1, and ephrin-A4 are still not detectable within the brain at E95 (Fig. 5, R-A1, R-A2, L-A1, L-A4, respectively); however, ephrin-A2 is now clearly expressed (Figs. $5, L-A 2,6, L-A 2)$. Each gene's expression pattern is detailed briefly below.

\section{$\operatorname{Eph} A 3$}

EphA3 expression at this age is tightly localized to the posteriormost one-third of the CP (Fig. 5R-A3). As at E80, EphA3 expression is consistent with its localization in presumptive layer IV at E95 (Fig. 6, R-A3).

\section{EphA4}

Although present throughout the E95 cerebral wall, levels of EphA4 are highest within the posterior half of the cortical plate. As at E80, the anterior border of EphA4 is more rostral than that of EphA3 (Fig. 5, R-A4). Moreover, EphA4 is present only in the deepest layers of the $\mathrm{CP}$, presumably future layers IV, V, and VI, as well as within the SP zone (Fig. 6, $R$ - $A 4$ ).

\section{EphA5}

The pattern of EphA5 expression in the E95 neocortex is significantly different from that seen at E80. In particular, in contrast with the fairly uniform expression at E80, EphA5 levels are high posteriorly, with very low anterior expression at E95 (Fig. 5, $R-A 5)$. Furthermore, EphA5 is present throughout the $\mathrm{CP}$ and SP but is now excluded from the MZ (Fig. 6, $R$ - $A 5$ ).

\section{EphA6}

As at E80, expression of EphA6 is restricted to the posterior-most region of the cerebral cortex (Fig. 5, $R$-A6) and continues to be tightly localized to the deepest CP and the SP zone (Fig. 6, $R-A 6)$.

\section{EphA7}

Although the highest levels of EphA7, like EphA6, are found in the posterior cortex, its expression remains more widespread in two respects. First, the anterior border of EphA7 expression extends more rostrally than that of EphA6; second, EphA7 is expressed in anterior regions of the cortex, although it is unclear to what prospective cytoarchitectonic areas these patches correspond (Fig. 5, $R-A 7$ ). EphA7 is expressed in SP and within the deepest layers of the $\mathrm{CP}$ (Fig. $6, R$ - $A 7$ ). Thus, as we observed at 
earlier ages, expression of EphA7 is similar to that of EphA6; however, it is considerably more extensive, both along the cortex's anteroposterior axis and within the cerebral wall.

\section{ephrin- $A 2$}

ephrin-A2, a gene that was not detectable at E65 or E80, is expressed throughout the cortical plate at E95 (Fig. 5, L-A2). Moreover, ephrin-A2 expression is most intense posteriorly, trailing off anteriorly. Although present in all presumptive layers, ephrin-A2 expression is most concentrated within the deepest strata of the $\mathrm{CP}$, consistent with its presence in cells that will populate future layers IV and V (Fig. 6, $L-A 2$ ).

\section{ephrin- $A 3$}

In contrast to most other members of the EphA and ephrin-A families, which display posterior-to-anterior gradients of expression, ephrin-A3 demonstrates an anterior-high-posterior-low pattern of expression at E95 (Fig. 5, L-A3). In fact, expression of ephrin-A3 has shifted more anteriorly, as compared with its E80 pattern, such that it is present only within the anterior-most two-thirds of the cortex and is absent from posterior regions (Figs. 3 and 5, compare $L-A 3$ ). Although it is present within all of the presumptive layers of the cortical plate anteriorly (data not shown), it is not detectable within the posterior cortical plate (Fig. 6, L-A3).

\section{ephrin-A5}

ephrin-A5 expression is restricted to the posterior-most twothirds of the cortex at E95 (Fig. 5, L-A5). Interestingly, a similar restriction in expression was observed for EphA5 from E80 to E95 (Figs. 3 and 5, compare $R-A 5$ with $L-A 5$ ). Moreover, ephrin-A5 demonstrates marked laminar specificity, in that it is expressed within two bands of cells within the E95 CP: a deep population, consistent with its presence within cells that will populate layer $\mathrm{V}$, and to a lesser extent, a more superficial population that is consistent with the formation of future layers II/III (Fig. 6, $L-A 5$ ).

Taken together, patterns within the E95 neocortex demonstrate that EphA and ephrin-A gene expression can either remain stable through development or change considerably, suggesting a functional role for some of them during cortical development.

\section{DISCUSSION}

In a search for genes that are differentially expressed by cells of the embryonic cerebral wall, especially within presumptive cytoarchitectonic areas, we examined the expression of the Eph receptors and their ligands, the ephrins, in the embryonic macaque monkey neocortex. Taking advantage of the spatial and temporal resolution of the primate cortex, we show here that EphA and ephrin-A family members are expressed in distinct patterns within the embryonic cerebral wall as well as in the cortical plate. Moreover, members of the EphA system are present in laminarspecific and embryonic zone-specific patterns. The fact that well defined patterns of gene expression are present early in cortical development, before innervation of the cortical plate by thalamic afferents, suggests that the expression of this group of molecules is regulated by programs intrinsic to cortical cells. Furthermore, the maintenance of early patterns of expression demonstrates that such programs are stable throughout corticogenesis. In addition to this stability, however, patterns of expression of other members of the EphA system change dramatically as development proceeds. Such refinements to initial patterns support the concept that extrinsic factors can alter a cortical cell's molecular repertoire. Thus, the distinct yet dynamic patterns of EphA system gene expression that we observe within the developing primate cerebral wall are likely to reflect both the intrinsically encoded cell specification and the influence of environmental signals.

It should be noted that we and others have examined this group of molecules in the developing neocortex of more experimentally accessible animals, such as rodents (Gale et al., 1996; Gao et al., 1998; our unpublished observations). Although patterns of EphA system members' gene expression are slightly regionalized within the embryonic rodent neocortex, they are more subtle (our unpublished observations). We believe that this difference reflects the sharper laminar, radial, and areal organization of the primate cortex (Sidman and Rakic, 1982; Hohl-Abrahao and Creutzfeldt, 1991). In particular, the striking separation of striate and extrastriate regions present in primates, both in their distinct patterns of connections and their cytoarchitectonic differentiation, is not obvious in rodents. Nonetheless, the fact that early emerging, if less pronounced, patterns of EphA and ephrin-A gene expression do exist within the rodent cortex suggests that similar rules govern the parcellation of smaller and less complex cortical systems and affirms that it is possible to manipulate gene expression in a more tractable system than primate, thus providing insight into the mechanisms and consequences of their actions during corticogenesis.

\section{Laminar distribution}

The expression of some members of the EphA and ephrin-A families suggest that they are present in distinct populations of cells in the developing neocortex, consistent with their marking distinct laminae as they form. In fact, both EphA3 and ephrin-A5 expression suggests future laminar specificity as soon as cells of the future layers have reached the cortical plate. When might such laminar specificity arise? In the case of EphA3, which is expressed by cells of the subventricular zone in a posterior bias that reflects its posteriorly restricted cortical plate expression, it is possible that future posterior layer IV cells are positive for EphA3 as soon as they become postmitotic and begin to migrate. Indeed, lineage, transplantation, and gene expression studies suggest that cells are biased toward specific phenotypes and layers before they reach the cortical plate (McConnell, 1988; Parnavelas et al., 1991; Frantz et al., 1994; Bulfone et al., 1995; Kornack and Rakic, 1995; Kuan et al., 1997; Tan et al., 1998). In contrast, ephrin-A5 is expressed exclusively by cells of the cortical plate, with no detectable expression in any of the other embryonic zones. Thus, ephrin-A5 expression appears to be activated only after a cell arrives in the cortical plate and begins to differentiate. Interestingly, even at relatively early stages, cells of the cortical plate already show a remarkable degree of differentiation, with obvious typical patterns of dendritic arborization (Shatz and Rakic, 1981). Thus, despite distinct timing and patterns of laminar distribution, EphA and ephrin-A gene expression appear to mark groups of cells that reside within defined layers of the cortical plate, once again demonstrating that members of this family may be useful for distinguishing between distinct populations of cortical cells early in development.

\section{Areal distribution}

We found that expression patterns of EphA and ephrin-A family members also demarcate regional cellular compartments of the cerebral wall, before either the clear morphological segregation of cells into cytoarchitectonic areas or the establishment of the 
stereotyped patterns of connectivity between the thalamus and the cortex. For example, EphA6 is expressed within a defined region of the posterior cortical plate at E65, an age at which this structure is still forming and is without reciprocal connections with the thalamus (Rakic, 1977b; Shatz and Rakic, 1981), suggesting that programs innate to cortical cells are regulating this patterned expression. Moreover, the fact that the restricted pattern of expression of EphA6 is maintained at both E80 and E95 reveals marked stability in the face of great changes in cellular composition and patterns of connections. Such stability is especially interesting because the domain within which EphA6 is expressed corresponds to the future visual cortex. Thus, EphA6 may be an early marker of a future functional domain, before that domain has received afferent input from the thalamus and exhibits explicit cytoarchitectonic specification. EphA6's expression is even more intriguing in light of the fact that it is restricted to the deepest layer of the cortical plate and the subplate zone, regions that have been implicated in determining the specificity of thalamocortical fibers (Rakic, 1977b; Kostovic and Rakic, 1984, 1990; McConnell et al., 1989; Blakemore and Molnar, 1990; Ghosh et al., 1990; De Carlos and O'Leary, 1992; Agmon et al., 1995). Other members of the EphA system also reveal early patterning, some of which delineate prospective functional areas. For example, expression of EphA3 at E65 corresponds to the boundaries of the future extrastriate cortex, leaving the striate cortex devoid of this marker. This finding hints that the embryonic occipital cortex undergoes hierarchical parcellation of functional subdivisions early in corticogenesis. Thus, molecular compartments exist, both in the cortical plate and in other embryonic zones, and these compartments precede obvious cellular changes.

We also observed considerable alterations in patterns of EphA and ephrin-A gene expression as primate corticogenesis proceeded. For example, ephrin-A5 is uniformly distributed at the beginning and middle stages of corticogenesis (E65 and E80) but is posteriorly biased at its end (E95). In contrast, ephrin-A3, also uniformly expressed early, shifts anteriorly by E95. Such changes in expression could reflect either intrinsically encoded alterations or, conversely, responses to extrinsic factors such as innervation by specific thalamic afferents (Rakic et al., 1991; Dehay et al., 1996, 1991) or retrograde induction via corticothalamic innervation, which has formed nucleus- and topographic-specific connections by this point (Shatz and Rakic, 1981). Although future studies will discern between these possibilities, a role for extrinsic influences is attractive because the time during which the most obvious shifts occur (E80-95) corresponds to the period within which thalamic axons begin to invade the cortical plate and form synapses as well as when cortical efferents contact their thalamic targets (Shatz and Rakic, 1981). Our working hypothesis in this regard is that the intrinsically regulated EphA system is involved in attracting appropriate thalamic inputs to particular cortical regions (see Functional considerations); however, after such inputs arrive, local cytoarchitectonic and synaptic features, as well as the final positions of areal borders, are determined by interactions between neocortical cells and thalamic axons (Rakic, 1988). This hypothesis is consistent with the fact that the final size of the striate cortex depends on the size of its geniculate input (Rakic et al., 1991; Dehay et al., 1996). Finally, a recent study suggests that the Eph system members are present in mature synapses, indicating that they may be functionally plastic as development proceeds (Torres et al., 1998).

It is intriguing that the prospective visual cortex and its subdivisions are the earliest and most prominently marked by expres- sion of the EphA system. For example, EphA6 is expressed only within the deep cortical plate and subplate of the occipital lobe throughout corticogenesis. Such specific patterning is not as surprising as it may seem, however, because the primate visual cortex is developmentally distinct. Specialization of magnocellular and parvocellular subsystems is apparent early and is independent of patterned activity (Kuljis and Rakic, 1990; Dehay et al., 1991; Rakic, 1991; Rakic et al., 1991; Rakic and Lidow, 1995; Bourgeois and Rakic, 1996; Meissirel et al., 1997; Snider et al., 1999), and other aspects of the visual cortex's functional organization are also established early and not modifiable by experience (Dehay and Kennedy, 1988; Kennedy and Dehay, 1993; Rakic and Lidow, 1995; Bourgeois and Rakic, 1996; Godecke and Bonhoeffer, 1996; Horton and Hocking, 1996; Murphy et al., 1998). Moreover, the superior colliculus, the midbrain visual center, develops normally in the absence of mature patterns of visual activity: receptive field properties develop properly in newborn monkeys (Wallace et al., 1997) and corticocollicular projections are normal in anophthalmic mice (Khachab and Bruce, 1999). The fact that EphA3 is expressed by presumptive extrastriate but not striate cortex at E65 suggests that hierarchical distinctions emerge early among visual subregions. Indeed, such early molecular distinctions are mirrored in the fact that layer IV cells of the striate and extrastriate cortex in primates, but not in most other species, eventually receive exclusive inputs from the spulvinar and lateral geniculate nuclei, respectively, of the thalamus (Benevento and Rezak, 1976; Hendrickson et al., 1978; Rezak and Benevento, 1979; Levitt et al., 1995). This is why the difference in distribution of EphA3 and EphA6 might not be expected in other species, where the projections of visual thalamic nuclei overlap. Nonetheless, similar distinctions between these cortical regions have been observed within subjacent segments of the subplate zone in human fetuses by acetylcholinesterase staining (Kostovic and Rakic, 1984). It remains to be determined, however, whether there is a relationship between EphA system expression and subsequent patterns of connectivity. Thus, the primate visual cortex may be unique, both in the clarity of its molecular patterning and in its early cellular parcellation, making it an especially useful system on which to focus in understanding how such distinctions arise in human.

\section{Functional considerations}

What might the functional consequences of such marked patterns of gene expression be on cortical development? Because the Eph receptors and their ligands have been implicated in axon guidance throughout the nervous system (Cheng et al., 1995; Drescher et al., 1995; Donoghue et al., 1996; Gao et al., 1998), it is likely that they function similarly in the developing neocortex. In particular, previous work demonstrating their differential expression in distinct regions of the nervous system, coupled with their differential effects on axon outgrowth, support the notion that these molecules may be involved in guiding thalamic axons either to appropriate cortical regions or laminar targets. In fact, the localization of some EphA receptors within the primate neocortex supports this idea. EphA6 is present in a defined region of the presumptive visual cortex, and within this region it is present in the deep cortical plate and the subplate zone, regions essential for the establishment of proper thalamocortical connectivity (Kostovic and Rakic, 1984, 1990; McConnell et al., 1989; Ghosh et al., 1990; De Carlos and O'Leary, 1992). In addition, EphA3 is expressed by prospective layer IV cells within the future visual region, the primary cortical target of the lateral geniculate nu- 
cleus of the thalamus. Thus, recognition of distinct presumptive functional domains could be mediated by the differential localization of particular EphA system family members, whether they are within guidance zones, such as the subplate, or within target areas, such as layer IV of the cortex. Whether the presence of these molecules results in repulsive or attractive interactions within the cerebral cortex remains an open question and one that needs to be examined in detail in the future. Nonetheless, molecular definitions of future functional domains could catalyze the formation of specific connections with subcortical structures.

Although we do not yet understand the exact roles that EphA and ephrin-A family members play in the developing cortex, their region-specific expression patterns are instructive because they demonstrate early compartmentalization of the embryonic cerebral wall. In particular, distinct yet restricted patterns of gene expression within the E65 subventricular, intermediate, and subplate zones, as well as in the cortical plate, reveal distinct molecular compartments that exist before the formation of connections with the periphery via the thalamus. Such findings argue that compartmentalized expression arises because of intrinsic programming of subsets of cortical plate cells soon after they exit the ventricular zone, rather than as a result of their induction by innervating axons. This conclusion stands in contrast to regionspecific cytoarchitectonic changes that occur after appropriate innervation of cortical regions by thalamic axons. The orderly patterns of gene expression that we document here raise the possibility that the EphA system may be involved in defining future functional domains that incoming axons can then recognize. Thus, the roles of these molecules in the initiation of cortical identity and the establishment of synaptic connections require further analysis.

\section{REFERENCES}

Agmon A, Yang LT, Jones EG, O’Dowd DK (1995) Topological precision in the thalamic projection to neonatal mouse barrel cortex. J Neurosci 15:549-561.

Arimatsu Y, Miyamoto M, Nihonmatsu I, Hirata K, Uratani Y, Hatanaka Y, Takiguchi-Hayashi K (1992) Early regional specification for a molecular neuronal phenotype in the rat neocortex. Proc Natl Acad Sci USA 89:8879-8883.

Barbe MF, Levitt P (1991) The early commitment of fetal neurons to the limbic cortex. J Neurosci 11:519-533.

Benevento LA, Rezak M (1976) The cortical projections of the inferior pulvinar and adjacent lateral pulvinar in the rhesus monkey (Macaca mulatta): an autoradiographic study. Brain Res 108:1-24.

Blakemore C, Molnar Z (1990) Factors involved in the establishment of specific interconnections between thalamus and cerebral cortex. Cold Spring Harb Symp Quant Biol 55:491-504.

Bourgeois JP, Rakic P (1993) Changes of synaptic density in the primary visual cortex of the macaque monkey from fetal to adult stages. J Neurosci 13:2801-2820.

Bourgeois J-P, Rakic P (1996) Synaptogenesis in the occipital cortex of macaque monkey devoid of retinal input from early embryonic stages. Eur J Neurosci 8:942-950.

Brodmann K (1909) Vergleichende Localisationsationslehre der Grosshir-hinde. Leipzig: Barth.

Bulfone A, Smiga SM, Shimamura K, Peterson A, Puelles L, Rubenstein JL (1995) T-brain-1: a homolog of Brachyury whose expression defines molecularly distinct domains within the cerebral cortex. Neuron 15:63-78

Castellani V, Yue Y, Gao PP, Zhou R, Bolz J (1998) Dual action of a ligand for Eph receptor tyrosine kinases on specific populations of axons during the development of cortical circuits. J Neurosci 18:4663-4672.

Cheng HJ, Nakamoto M, Bergemann AD, Flanagan JG (1995) Complementary gradients in expression and binding of ELF-1 and Mek4 in development of the topographic retinotectal projection map. Cell 82:371-381.
Cohen-Tannoudji M, Babinet C, Wassef M (1994) Early determination of a mouse somatosensory cortex marker. Nature 368:460-463.

Creutzfeldt OD (1977) Generality of the functional structure of the neocortex. Naturwissenschaften 64:507-517.

De Carlos JA, O'Leary DD (1992) Growth and targeting of subplate axons and establishment of major cortical pathways. J Neurosci 12:1194-1211.

Dehay C, Kennedy H (1988) The maturational status of thalamocortical and callosal connections of visual areas V1 and V2 in the newborn monkey. Behav Brain Res 29:237-244.

Dehay C, Horsburgh G, Berland M, Killackey H, Kennedy H (1991) The effects of bilateral enucleation in the primate fetus on the parcellation of visual cortex. Brain Res Dev Brain Res 62:137-141.

Dehay C, Giroud P, Berland M, Smart I, Kennedy H (1993) Modulation of the cell cycle contributes to the parcellation of the primate visual cortex. Nature 366:464-466.

Dehay C, Giroud P, Berland M, Killackey H, Kennedy H (1996) Contribution of thalamic input to the specification of cytoarchitectonic cortical fields in the primate: effects of bilateral enucleation in the fetal monkey on the boundaries, dimensions, and gyrification of striate and extrastriate cortex. J Comp Neurol 367:70-89.

Donoghue MJ, Lewis RM, Merlie JP, Sanes JR (1996) The Eph kinase ligand AL-1 is expressed by rostral muscles and inhibits outgrowth from caudal neurons. Mol Cell Neurosci 8:185-198.

Drescher U, Kremoser C, Handwerker C, Loschinger J, Noda M, Bonhoeffer F (1995) In vitro guidance of retinal ganglion cell axons by RAGS, a $25 \mathrm{kDa}$ tectal protein related to ligands for Eph receptor tyrosine kinases. Cell 82:359-370.

Eagleson KL, Lillien L, Chan AV, Levitt P (1997) Mechanisms specifying area fate in cortex include cell-cycle-dependent decisions and the capacity of progenitors to express phenotype memory. Development 124:1623-1630.

Eph Nomenclature Committee (1997) Unified nomenclature for Eph family receptors and their ligands, the ephrins. Cell 90:403-404.

Feldheim DA, Vanderhaeghen P, Hansen MJ, Frisen J, Lu Q, Barbacid M, Flanagan JG (1998) Topographic guidance labels in a sensory projection to the forebrain. Neuron 21:1303-1313.

Ferri RT, Levitt P (1993) Cerebral cortical progenitors are fated to produce region-specific neuronal populations. Cereb Cortex 3:187-198.

Frantz GD, Bohner AP, Akers RM, McConnell SK (1994) Regulation of the POU domain gene SCIP during cerebral cortical development. J Neurosci 14:472-485.

Frisen J, Yates PA, McLaughlin T, Friedman GC, O'Leary DD, Barbacid M (1998) ephrin-A5 (AL-1/RAGS) is essential for proper retinal axon guidance and topographic mapping in the mammalian visual system. Neuron 20:235-243.

Fukushima M, Nakamura M, Ohta K, Okamura R, Negi A (1996) Regional specification of motoneurons along the anterior-posterior axis is independent of the notochord. Development 122:905-914.

Gale NW, Holland SJ, Valenzuela DM, Flenniken A, Pan L, Ryan TE, Henkemeyer M, Strebhardt K, Hirai H, Wilkinson DG, Pawson T, Davis S, Yancopoulos GD (1996) Eph receptors and ligands comprise two major specificity subclasses and are reciprocally compartmentalized during embryogenesis. Neuron 17:9-19.

Gao PP, Yue Y, Zhang JH, Cerretti DP, Levitt P, Zhou R (1998) Regulation of thalamic neurite outgrowth by the Eph ligand ephrin-A5: implications in the development of thalamocortical projections. Proc Natl Acad Sci USA 95:5329-5334.

Ghosh A, Antonini A, McConnell SK, Shatz CJ (1990) Requirement for subplate neurons in the formation of thalamocortical connections. Nature 347:179-181.

Godecke I, Bonhoeffer T (1996) Development of identical orientation maps for two eyes without common visual experience. Nature 379:251-254.

Hendrickson AE, Wilson JR, Ogren MP (1978) The neuroanatomical organization of pathways between the dorsal lateral geniculate nucleus and visual cortex in Old World and New World primates. J Comp Neurol 182:123-136.

Hohl-Abrahao JC, Creutzfeldt OD (1991) Topographical mapping of the thalamocortical projections in rodents and comparison with that in primates. Exp Brain Res 87:283-294.

Horton JC, Hocking DR (1996) An adult-like pattern of ocular dominance columns in striate cortex of newborn monkeys prior to visual experience. J Neurosci 16:1791-1807. 
Kennedy H, Dehay C (1993) Cortical specification of mice and men. Cereb Cortex 3:171-186.

Khachub MY, Bruce LL (1999) The development of corticocollicular projections in anophthalmic mice. Dev Brain Res 114:179-192.

Kornack DR, Rakic P (1995) Radial and horizontal deployment of clonally related cells in the primate neocortex: relationship to distinct mitotic lineages. Neuron 15:311-321.

Kostovic I, Rakic P (1984) Development of prestriate visual projections in the monkey and human fetal cerebrum revealed by transient cholinesterase staining. J Neurosci 4:25-42.

Kostovic I, Rakic P (1990) Developmental history of the transient subplate zone in the visual and somatosensory cortex of the macaque monkey and human brain. J Comp Neurol 297:441-470.

Krull CE, Lansford R, Gale NW, Collazo A, Marcelle C, Yancopoulos GD, Fraser SE, Bronner-Fraser M (1997) Interactions of Eph-related receptors and ligands confer rostrocaudal pattern to trunk neural crest migration. Curr Biol 7:571-580.

Kuan CY, Elliott EA, Flavell RA, Rakic P (1997) Restrictive clonal allocation in the chimeric mouse brain. Proc Natl Acad Sci USA 94:3374-3379.

Kuljis RO, Rakic P (1990) Hypercolumns in primate visual cortex can develop in the absence of cues from photoreceptors. Proc Natl Acad Sci USA 87:5303-5306.

Levitt JB, Yoshioka T, Lund JS (1995) Connections between the pulvinar complex and cytochrome oxidase-defined compartments in visual area V2 of macaque monkey. Exp Brain Res 104:419-430.

Luskin MB, Pearlman AL, Sanes JR (1988) Cell lineage in the cerebral cortex of the mouse studied in vivo and in vitro with a recombinant retrovirus. Neuron 1:635-647.

McConnell SK (1988) Fates of visual cortical neurons in the ferret after isochronic and heterochronic transplantation. J Neurosci 8:945-974.

McConnell SK, Ghosh A, Shatz CJ (1989) Subplate neurons pioneer the first axon pathway from the cerebral cortex. Science 245:978-982.

Meissirel C, Wikler KC, Chalupa LM, Rakic P (1997) Early divergence of magnocellular and parvocellular functional subsystems in the embryonic primate visual system. Proc Natl Acad Sci USA 94:5900-5905.

Melton DA, Krieg PA, Rebagliati MR, Maniatis T, Zinn K, Green MR (1984) Efficient in vitro synthesis of biologically active RNA and RNA hybridization probes from plasmids containing a bacteriophage SP6 promoter. Nucleic Acids Res 12:7035-7056.

Molnar Z, Adams R, Blakemore C (1998) Mechanisms underlying the early establishment of thalamocortical connections in the rat. J Neurosci 18:5723-5745.

Murphy KM, Jones DG, Fenstemaker SB, Pegado VD, Kiorpes L, Movshon JA (1998) Spacing of cytochrome oxidase blobs in visual cortex of normal and strabismic monkeys. Cereb Cortex 8:237-244.

Na E, McCarthy M, Neyt C, Lai E, Fishell G (1998) Telencephalic progenitors maintain anteroposterior identities cell autonomously. Curr Biol 8:987-990.

Nothias F, Fishell G, Ruiz i Altaba A (1998) Cooperation of intrinsic and extrinsic signals in the elaboration of regional identity in the posterior cerebral cortex. Curr Biol 8:459-462.

O'Leary DD (1989) Do cortical areas emerge from a protocortex? Trends Neurosci 12:400-406.

Pandey A, Lindberg RA, Dixit VM (1995) Cell signaling. Receptor orphans find a family. Curr Biol 5:986-989.

Parnavelas JG, Barfield JA, Franke E, Luskin MB (1991) Separate progenitor cells give rise to pyramidal and nonpyramidal neurons in the rat telencephalon. Cereb Cortex 1:463-468.

Patel K, Nittenberg R, D'Souza D, Irving C, Burt D, Wilkinson DG, Tickle C (1996) Expression and regulation of Cek-8, a cell to cell signaling receptor in developing chick limb buds. Development 122:1147-1155.

Polleux F, Dehay C, Moraillon B, Kennedy H (1997) Regulation of neuroblast cell-cycle kinetics plays a crucial role in the generation of unique features of neocortical areas. J Neurosci 17:7763-7783.

Rakic P (1972) Mode of cell migration to the superficial layers of fetal monkey neocortex. J Comp Neurol 145:61-83.

Rakic P (1974) Neurons in rhesus monkey visual cortex: systematic relation between time of origin and eventual disposition. Science 183:425-427.

Rakic P (1976) Prenatal genesis of connections subserving ocular dominance in the rhesus monkey. Nature 261:467-471.
Rakic P (1977a) Genesis of the dorsal lateral geniculate nucleus in the rhesus monkey: site and time of origin, kinetics of proliferation, routes of migration and pattern of distribution of neurons. J Comp Neurol 176:23-52.

Rakic P (1977b) Prenatal development of the visual system in rhesus monkey. Philos Trans R Soc Lond B Biol Sci 278:245-260.

Rakic P (1988) Specification of cerebral cortical areas. Science 241:170-176.

Rakic P (1991) Plasticity of cortical development. In: Plasticity of development (Brauth SE, Doolings RJ, eds), pp 127-161. Cambridge, MA: MIT.

Rakic P, Lidow MS (1995) Distribution and density of monoamine receptors in the primate visual cortex devoid of retinal input from early embryonic stages. J Neurosci 15:2561-2574.

Rakic P, Suner I, Williams RW (1991) A novel cytoarchitectonic area induced experimentally within the primate visual cortex. Proc Natl Acad Sci USA 88:2083-2087.

Rezak M, Benevento LA (1979) A comparison of the organization of the projections of the dorsal lateral geniculate nucleus, the inferior pulvinar and adjacent lateral pulvinar to primary visual cortex (area 17) in the macaque monkey. Brain Res 167:19-40.

Roe AW, Pallas SL, Hahm JO, Sur M (1990) A map of visual space induced in primary auditory cortex. Science 250:818-820.

Sambrook J, Fritsch EF, Maniatis T (1989) Molecular cloning: a laboratory manual. Cold Spring Harbor, NY: Cold Spring Harbor Laboratory.

Schlaggar BL, O’Leary DD (1991) Potential of visual cortex to develop an array of functional units unique to somatosensory cortex. Science 252:1556-1560.

Shatz CJ, Rakic P (1981) The genesis of efferent connections from the visual cortex of the fetal rhesus monkey. J Comp Neurol 196:287-307.

Sidman RL, Rakic P (1973) Neuronal migration, with special reference to developing human brain: a review. Brain Res 62:1-35.

Sidman RL, Rakic P (1982) Development of the human central nervous system. In: Histology and histopathology of the nervous system (Adams D, ed), pp 3-145. Springfield, IL: C. C. Thomas.

Smith A, Robinson V, Patel K, Wilkinson DG (1997) The EphA4 and EphB1 receptor tyrosine kinases and ephrin-B2 ligand regulate targeted migration of branchial neural crest cells. Curr Biol 7:561-570.

Snider CJ, Dehay C, Berland M, Kennedy H, Chalupa LM (1999) Prenatal development of retinogeniculate axons in the macaque monkey during segregation of binocular inputs. J Neurosci 19:220-228.

Sur M, Garraghty PE, Roe AW (1988) Experimentally induced visual projections into auditory thalamus and cortex. Science 242:1437-1441.

Tan S-S, Kallontiatis M, Sturm K, Tam PPL, Reese BE, Faulkner-Jones B (1998) Separate progenitors for radial and tangential cell dispersion during development of the cerebral neocortex. Neuron 21:295-304.

Torres R, Firestein BL, Dong H, Staudinger J, Olson E, Huganir RL, Bredt DS, Gale NW, Yancopoulos GD (1998) PDZ proteins bind, cluster, synaptically colocalize with Eph receptors and their ephrin ligands. Neuron 21:1453-1463.

Tuzi NL, Gullick WJ (1994) eph, the largest known family of putative growth factor receptors. Br J Cancer 69:417-421.

Wallace MT, McHaffie JG, Stein BE (1997) Visual response and visuotopic representation in the newborn monkey superior colliculus. J Neurophysiol 78:2732-2741.

Wang HU, Anderson DJ (1997) Eph family transmembrane ligands can mediate repulsive guidance of trunk neural crest migration and motor axon outgrowth. Neuron 18:383-396.

Wang HU, Chen ZF, Anderson DJ (1998) Molecular distinction and angiogenic interaction between embryonic arteries and veins revealed by ephrin-B2 and its receptor Eph-B4. Cell 93:741-753.

Winslow JW, Moran P, Valverde J, Shih A, Yuan JQ, Wong SC, Tsai SP, Goddard A, Henzel WJ, Hefti F, Beck KD, Caras IW (1995) Cloning of AL-1, a ligand for an Eph-related tyrosine kinase receptor involved in axon bundle formation. Neuron 14:973-981.

Zhang JH, Cerretti DP, Yu T, Flanagan JG, Zhou R (1996) Detection of ligands in regions anatomically connected to neurons expressing the Eph receptor Bsk: potential roles in neuron-target interaction. J Neurosci 16:7182-7192. 